\title{
A Large-angle X-Ray Scattering Investigation of Some Polynuclear Molybdoarsenate Complexes in Aqueous Solution
}

\author{
GEORG JOHANSSON, ${ }^{a}$ LAGE PETTERSSON $^{\mathrm{b}}$ and NILS INGRI ${ }^{\mathrm{b}}$
}

${ }^{a}$ Department of Inorganic Chemistry, Royal Institute of Technology, S-100 44 Stockholm 70, Sweden and

${ }^{b}$ Department of Inorganic Chemistry, University of Umeå, S-901 87 Umeå, Sweden

The structures of heteropoly complexes formed in aqueous $\mathrm{H}^{+}-\mathrm{MoO}_{4}^{2-}-\mathrm{HAsO}_{4}^{2-}$ solutions have been investigated by large-angle $\mathrm{X}$-ray scattering (LAXS) measurements. The complexes $\left(\mathrm{H}^{+}\right)_{p^{-}}$ $\left(\mathrm{MoO}_{4}^{2-}\right)_{9}\left(\mathrm{HAsO}_{4}^{2-}\right)$, with $p=14-16$, present at $\mathrm{Mo} /$ As ratios $\sim 9$ according to results of potentiometric measurements, have been shown to have the same basic structure as the discrete units $\mathrm{Mo}_{9} \mathrm{AsO}_{31}\left(\mathrm{OH}_{2}\right)_{3}^{3-}$ found in the crystalline compound $\mathrm{Na}_{3} \mathrm{Mo}_{9} \mathrm{AsO}_{31}\left(\mathrm{OH}_{2}\right)_{3} .12-13 \mathrm{H}_{2} \mathrm{O}$. The complex $\left(\mathrm{H}^{+}\right)_{12}\left(\mathrm{MoO}_{4}^{2-}\right)_{6}\left(\mathrm{HAsO}_{4}^{2-}\right)_{2}$, which according to potentiometric measurements should be dominant in acid solutions at Mo/As ratios $\sim 3$, is shown by the scattering data to lack long Mo-Mo distances and, therefore, may contain fewer than six Mo atoms.

In the aqueous system $\mathrm{H}^{+}-\mathrm{MoO}_{4}^{2-}-\mathrm{HAsO}_{4}^{2-}$, heteropoly complexes are formed according to the reaction

$p \mathrm{H}^{+}+q \mathrm{MoO}_{4}^{2-}+r \mathrm{HAsO}_{4}^{2-} \rightleftharpoons$ $\left(\mathrm{H}^{+}\right)_{p}\left(\mathrm{MoO}_{4}^{2-}\right)_{q}\left(\mathrm{HAsO}_{4}^{2-}\right)_{r}$

Potentiometric and spectrophotometric measurements by Pettersson ${ }^{1,2}$ have been interpreted by assuming the formation of two series of complexes. For Mo/As ratios $\sim 9$ the predominant complexes found are $\left(\mathrm{H}^{+}\right)_{p}\left(\mathrm{MoO}_{4}^{2-}\right)_{9}\left(\mathrm{HAsO}_{4}^{2-}\right)$ with $p=14,15$, 16 and 17. For $\mathrm{Mo} / \mathrm{As}$ ratios $\sim 3$ the species $\left(\mathrm{H}^{+}\right)_{p}\left(\mathrm{MoO}_{4}^{2-}\right)_{6}\left(\mathrm{HAsO}_{4}^{2-}\right)_{2}$ with $p=10,11$ and 12, and, to a minor extent, $\left(\mathrm{H}^{+}\right)_{8}\left(\mathrm{MoO}_{4}^{2-}\right)_{5}\left(\mathrm{HAsO}_{4}^{2-}\right)_{2}$, are dominant. For the analogous system $\mathrm{H}^{+}-\mathrm{MoO}_{4}^{2-}-\mathrm{HPO}_{4}^{2-}$ potentiometric and spectrophotometric measurements were explained by a similar set of complexes, excluding those containing six molybdenum atoms. ${ }^{2,3}$ In the following, the complexes formed will often the denoted by their $p, q$ and $r$ values only, thus $(14,9,1)$ will indicate the complex $\left(\mathrm{H}^{+}\right)_{14}\left(\mathrm{MoO}_{4}^{2-}\right)_{9}\left(\mathrm{HAsO}_{4}^{2-}\right)$ or, written differently, $\mathrm{Mo}_{9} \mathrm{AsO}_{31}(\mathrm{OH})_{3}^{6-}$, which is equivalent because the number of water molecules in the formula cannot be determined from equilibrium analyses in aqueous solution.

Crystals containing discrete $(17,9,1)$ complexes as well as discrete $(8,5,2),(9,5,2)$ and $(10,5,2)$ complexes have been obtained from the molybdophosphate system and the crystal structures have been determined. The structures of the complexes in solution have been shown by X-ray scattering measurements to be basically the same as those in the crystals. ${ }^{4,5}$ Therefore, the correct formula for a $(17,9,1)$ complex is $\mathrm{Mo}_{9} \mathrm{PO}_{31}\left(\mathrm{OH}_{2}\right)_{3}^{3-},\left[\mathrm{Mo}_{9} \mathrm{PO}_{31^{-}}\right.$ $\left.\left(\mathrm{OH}_{2}\right)_{3}^{3-}+6 \mathrm{H}_{2} \mathrm{O}=\left(\mathrm{H}^{+}\right)_{17}\left(\mathrm{MoO}_{4}^{2-}\right)_{9}\left(\mathrm{HPO}_{4}^{2-}\right)\right]$, and for an $(8,5,2)$ complex $\mathrm{Mo}_{5} \mathrm{P}_{2} \mathrm{O}_{23}{ }^{6-}$, $\left[\mathrm{Mo}_{5} \mathrm{P}_{2} \mathrm{O}_{23}^{6-}+5 \mathrm{H}_{2} \mathrm{O}=\left(\mathrm{H}^{+}\right)_{8}\left(\mathrm{MoO}_{4}^{2-}\right)_{5}\left(\mathrm{HPO}_{4}^{2-}\right)_{2}\right]$. Also from the molybdoarsenate system crystals can be obtained which according to a crystal structure determination contain discrete $(17,9,1)$ complexes having the same structure as the corresponding molybdophosphate. $^{6}$ It has not, however, been possible to prepare crystals containing $(p, 6,2)$ or $(p, 5,2)$ complexes from the molybdoarsenate solutions.

In order to obtain information on the structures of the molybdoarsenate complexes in solution, the $\mathrm{X}$-ray scattering has been measured from solutions which, according to results from the potentiometric measurements, should contain optimal amounts of the different complexes. 
Table 1. Compositions of solutions.

\begin{tabular}{|c|c|c|c|c|c|c|c|c|}
\hline & $\begin{array}{l}\text { A } \\
(14,9,1)\end{array}$ & $\begin{array}{l}\text { B } \\
(15,9,1)\end{array}$ & $\begin{array}{l}\mathrm{C} \\
(15,9,1)\end{array}$ & $\begin{array}{l}\mathrm{D} \\
(16,9,1)\end{array}$ & $\begin{array}{l}E \\
(12,6,2)\end{array}$ & $\begin{array}{l}\mathrm{F} \\
(12,6,2)\end{array}$ & $\begin{array}{l}G \\
(8,5,2)\end{array}$ & $\begin{array}{l}\mathrm{H} \\
(8,7,0)\end{array}$ \\
\hline \multicolumn{9}{|c|}{ Concentrations in $\mathrm{mol} / \mathrm{l}$} \\
\hline Mo & 1.608 & 1.608 & 1.600 & 1.600 & 1.608 & 1.400 & 1.770 & 2.040 \\
\hline As & 0.178 & 0.178 & 0.178 & 0.178 & 0.536 & 0.467 & - & - \\
\hline $\mathrm{Na}$ & 1.072 & 0.893 & 3.556 & 3.556 & 1.072 & 3.733 & 4.250 & 4.080 \\
\hline $\mathrm{Cl}$ & - & - & 2.667 & 2.844 & - & 2.800 & 2.120 & 2.330 \\
\hline $\mathrm{O}$ & 58.4 & 58.3 & 61.8 & 61.9 & 58.8 & 62.1 & 69.5 & 61.9 \\
\hline $\mathrm{H}$ & 105.2 & 105.1 & 90.9 & 89.8 & 104.1 & 90.0 & 91.7 & 91.1 \\
\hline$P$ & - & - & - & - & - & - & 0.710 & - \\
\hline \multicolumn{9}{|c|}{ Number of atoms in the unit of volume, $\mathrm{V}$} \\
\hline Mo & 1 & 1 & 1 & 1 & 1 & 1 & 1 & 1 \\
\hline As & 0.111 & 0.111 & 0.111 & 0.111 & 0.333 & 0.333 & - & - \\
\hline $\mathrm{Na}$ & 0.667 & 0.556 & 2.223 & 2.223 & 0.667 & 2.666 & 2.401 & 2.000 \\
\hline $\mathrm{Cl}$ & - & - & 1.667 & 1.778 & - & 2.000 & 1.198 & 1.142 \\
\hline O & 36.3 & 36.8 & 38.6 & 38.7 & 36.5 & 47.3 & 35.3 & 30.3 \\
\hline $\mathrm{H}$ & 65.4 & 65.4 & 56.8 & 56.1 & 64.8 & 64.3 & 51.8 & 44.7 \\
\hline $\mathbf{P}$ & - & - & - & - & - & - & 0.401 & - \\
\hline$V / \AA^{3}$ & 1032.7 & 1032.7 & 1037.8 & 1037.8 & 1032.7 & 1186.1 & 938.2 & 814.0 \\
\hline$\rho_{0} / \mathrm{el}^{2} \AA^{-3}$ & 161.3 & 159.7 & 207.1 & 208.4 & 168.4 & 241.4 & 196.2 & 168.9 \\
\hline
\end{tabular}

\section{EXPERIMENTAL}

The compositions of the six solutions, $A-F$, used for the X-ray scattering measurements are given in Table 1. The total concentration of molybdenum was kept as high as possible and the composition of each solution was chosen so as to yield an optimal amount of one of the complexes. The best compositions were selected by means of the stability constants given by Pettersson ${ }^{1}$ (Fig. 1). These constants were derived from potentiometric measurements performed in solutions containing $3 \mathrm{M} \mathrm{Na}\left(\mathrm{ClO}_{4}\right)$ as the ionic medium but with the highest molybdate concentration less than about one tenth of that used here. For the analysis of the scattering data two reference solutions, $\mathrm{G}$ and $\mathrm{H}$, were used (Table 1). As shown in a previous work ${ }^{4}$ all molybdenum in these solutions should occur as $\mathrm{Mo}_{5} \mathrm{P}_{2} \mathrm{O}_{23}^{6-}$ (G) or as $\mathrm{Mo}_{7} \mathrm{O}_{24}^{6-}(\mathrm{H})$ complexes, the structures of which are known.

Preparation of solutions: The solutions were prepared either by adding a standarized $\mathrm{NaOH}$ solution to weighed amounts of $\mathrm{MoO}_{3}$ (Merck p.a.) and $\mathrm{Na}_{2} \mathrm{HAsO}_{4} .7 \mathrm{H}_{2} \mathrm{O}$ (Merck p.a.) (solutions $\mathrm{A}, \mathrm{B}$ and $\mathrm{E}$ ), or by adding a standardized $\mathrm{HClO}_{4}$ solution to weighed amounts of $\mathrm{Na}_{2} \mathrm{MoO}_{4} \cdot 2 \mathrm{H}_{2} \mathrm{O}$ (Mallinckrodt p.a.) and $\mathrm{Na}_{2} \mathrm{HAsO}_{4} .7 \mathrm{H}_{2} \mathrm{O}$ (Merck p.a.) (solutions $\mathrm{C}, \mathrm{D}$ and $\mathrm{F}$ ). The first procedure was used for the $(14,9,1)$ solution $(A)$ in order to prevent a precipitation of isopolymolybdates, and for one
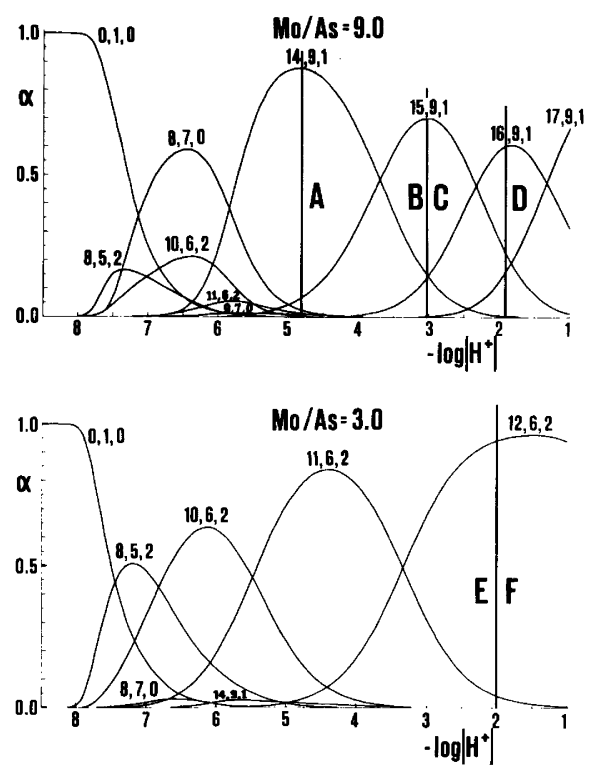

Fig. 1. The fraction, $\alpha$, of molybdenum bound in different complexes as a function of $-\log \left[\mathrm{H}^{+}\right]$. The total concentration of molybdenum is $1.60 \mathrm{M}$. The stability constants given by Pettersson ${ }^{1}$ have been used for the calculation. The compositions of the solutions, $\mathrm{A}-\mathrm{F}$, used for the scattering measurements are indicated by vertical lines.

Acta Chem. Scand. A 32 (1978) No. 8 
of the $(12,6,2)$ solutions $(E)$ in order to reach the same total molybdenum concentration $(1.60 \mathrm{M})$ as for the other solutions. With the second procedure the molybdenum concentration of the $(12,6,2)$ solution could not be increased beyond about 1.40 $M(F)$. Two $(15,9,1)$ solutions having equal concentrations of molybdate were prepared, one (B) by

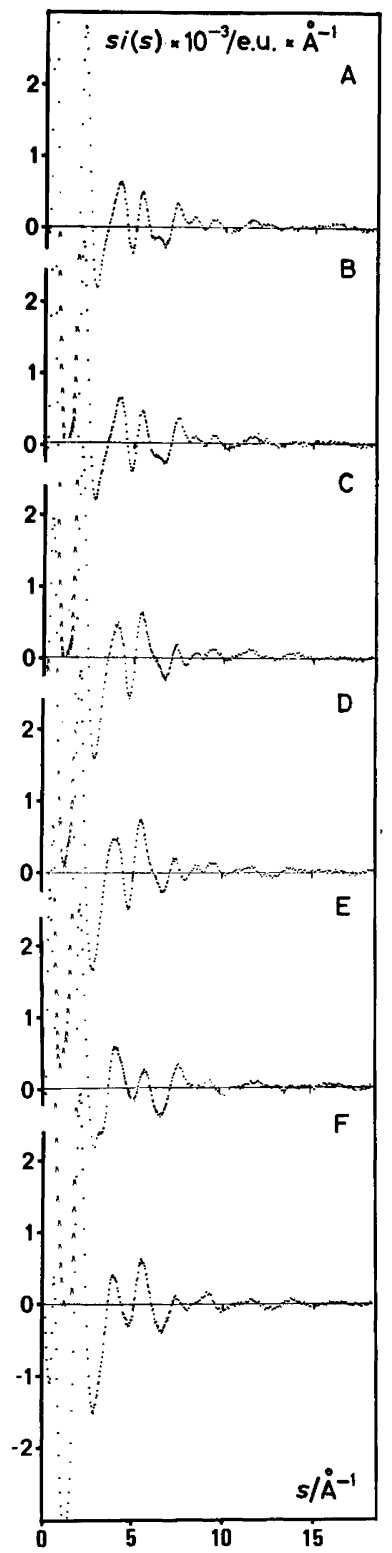

Fig. 2. Reduced intensity values, si(s), as a function of $s$ for the six solutions investigated. means of the first procedure and therefore holding a low concentration of $\mathrm{Na}^{+}$with no $\mathrm{ClO}_{4}^{-}$and the other $(\mathrm{C})$ by the second procedure resulting in a high concentration of $\mathrm{NaClO}_{4}$. They were both subjected to diffraction measurements in order to study the influence of the presence of sodium perchlorate in the solutions.

$X$-Ray measurements. The scattering measurements and the treatment of the X-ray data were carried out as described in previous papers. ${ }^{4,7-9}$ $\operatorname{Ag} K \alpha$ radiation $(\lambda=0.5608 \AA)$ was used and the scattering data were normalized to a stoichiometric unit of volume containing one molybdenum atom. The scattering factors, $f_{i}$, were taken from the same sources as in the previous work. ${ }^{4}$

The reduced intensity functions, $i(s)=I(s)-\sum_{i} f_{i}^{2}$, multiplied by $s=4 \pi \sin \theta / \lambda$ are shown in Fig. 2 for the six solutions investigated. The radial distribution functions were calculated according to the expression $D(r)=4 \pi r^{2} \rho_{0}+(2 r / \pi) \int_{s i(s) M(s)}^{s_{\max }} \sin (r s) \mathrm{d} s$ with $M(s)=\left\{f_{\mathrm{Mo}}^{2}(0) / f_{\mathrm{Mo}}^{2}(s)\right\} \exp \left(\stackrel{0}{-2} 0.01 s^{2}\right){ }^{9}$

The functions $D(r)-4 \pi r^{2} \rho_{0}$ for the six molybdoarsenate solutions, $A-F$, and the two reference solutions, $\mathrm{G}$ and $\mathrm{H}$, are compared in Fig. 3.

\section{ANALYSIS OF DATA}

A comparison between the distribution functions (Fig. 3) for the solutions A to D, i.e. those solutions that according to the potentiometric measurements (Fig. 1) should contain the complexes $(14,9,1)$, $(15,9,1)$, or $(16,9,1)$, shows no significant differences apart from those that can be ascribed to the presence of perchlorate in two of the solutions (C and $D$ ) but not in the other two (A and $\mathrm{B}$ ). This is consistent with the deductions from the potentiometric measurements that the dominant complexes in these solutions differ only in the number of protons. ${ }^{1}$

The two solutions $\mathrm{E}$ and $\mathrm{F}$, which according to the same investigation ${ }^{1}$ should contain the complex $(12,6,2)$ also are similar apart from differences ascribable to the presence of perchlorate in solution $\mathrm{F}$ but not in solution $\mathrm{E}$.

Because of these similarities the following analysis will be limited to only two of the solutions: C, containing the $(15,9,1)$ complex, and $F$ containing the $(12,6,2)$ complex. Both of these solutions contain perchlorate which makes their compositions correspond more closely to those of the two reference solutions $\mathrm{G}$ and $\mathrm{H}$ (Table 1).

A comparison between the distribution functions for the $(15,9,1)$ solution (C) and a corresponding 

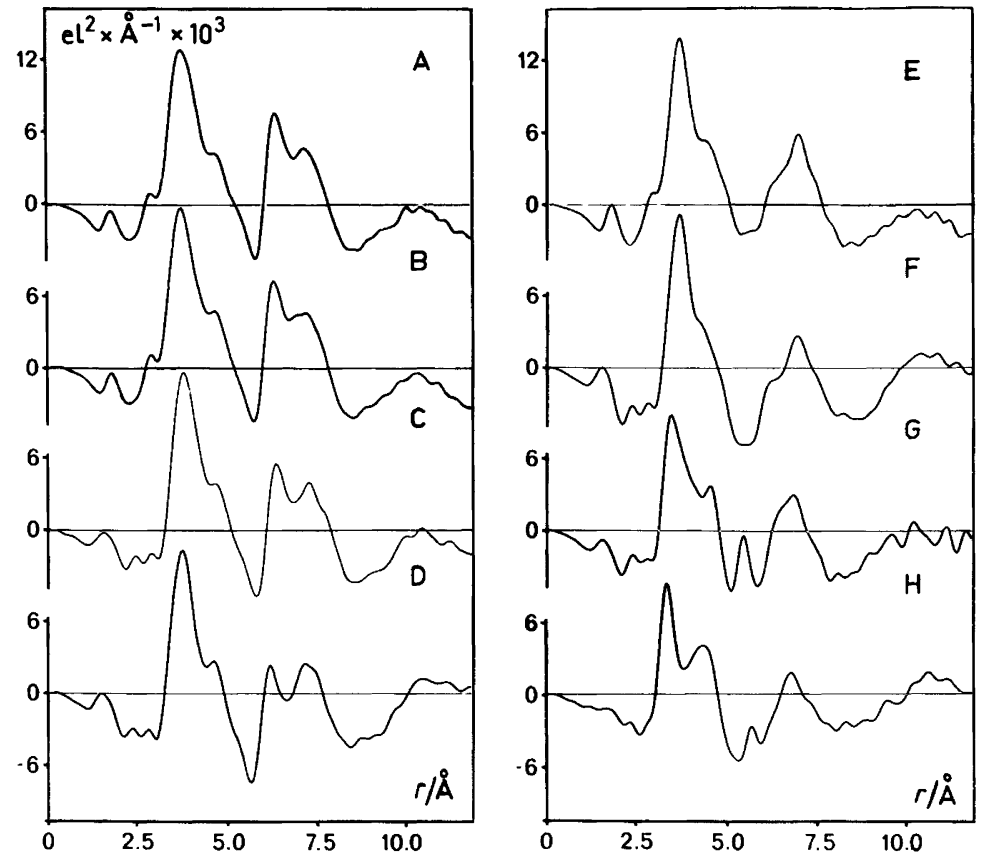

Fig. 3. The functions $D(r)-4 \pi r^{2} \rho_{0}$ for the six investigated solutions of the molybdoarsenate system $(\mathrm{A}-\mathrm{F})$ and for the two reference solutions $(\mathrm{G}$ and $\mathrm{H})$.

solution for the phosphate system, previously shown ${ }^{5}$ to contain the molybdenum bonded in $\mathrm{Mo}_{9} \mathrm{PO}_{34}$ groups, is shown in Fig. 4 together with the shape functions calculated from the crystal structure parameters for the complexes $\mathrm{Mo}_{9} \mathrm{AsO}_{31^{-}}$ $\left(\mathrm{OH}_{2}\right)_{3}^{3-6}$ and $\mathrm{Mo}_{9} \mathrm{PO}_{31}\left(\mathrm{OH}_{2}\right)_{3}^{3-} \cdot{ }^{10}$ It is obvious that the distribution function for the arsenate solution shows the features expected for a dominant complex of this type.

From Fig. 3 a similar comparison can be made between the $(12,6,2)$ solution $(F)$ and a corresponding solution in the phosphate system $(\mathrm{G})$, previously shown to contain all molybdenum bonded in $\mathrm{Mo}_{5} \mathrm{P}_{2} \mathrm{O}_{23}^{6-}$ complexes. The two curves do not agree and cannot, therefore, correspond to similar complexes. This is consistent with the conclusions from the potentiometric measurements.

In order to separate, as far as possible, the intramolecular interactions of the unknown molybdoarsenate complexes from those of other interactions in the solution a procedure was used which has been described in a previous paper. ${ }^{5}$ It makes use of the scattering data from a closely related reference solution containing complexes for which

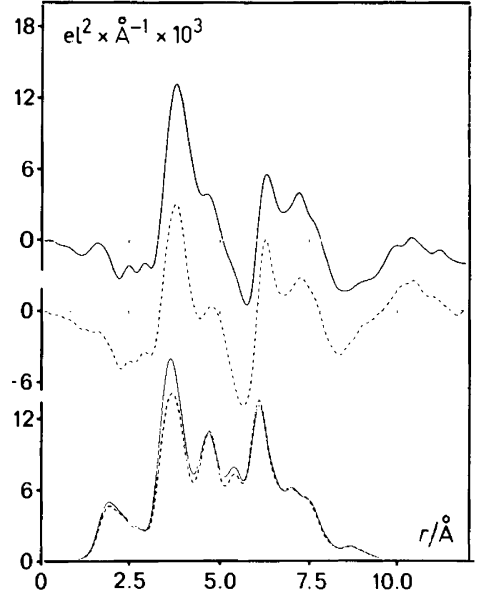

Fig. 4. A comparison between the $D(r)-4 \pi r^{2} \rho_{0}$ functions for a $(15,9,1)$ solution in the molybdoarsenate system (solid line) and in the phosphate system (dashed line). In the lower part of the figure are given the shape functions, calculated from the crystal structure parameters, for an $\mathrm{Mo}_{9} \mathrm{AsO}_{34}$ group (solid line) and an $\mathrm{Mo}_{9} \mathrm{PO}_{34}$ group (dashed line). 
the structures are known. A theoretical distribution curve can be calculated for this solution, if a suitable approximation to the intermolecular interactions can be found, for example by assuming the complexes to occupy spherical holes in an evenly distributed electron density. Deviations from the distribution function calculated from the experimental intensities result from intermolecular interactions not taken into account by the idealized model. By assuming the same deviations to be applicable to the solution under investigation an approximate shape function for the unknown com-

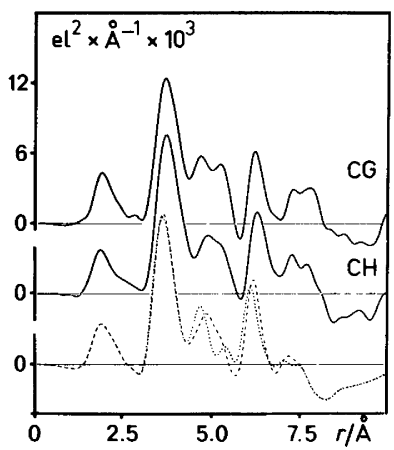

Fig. 5. The shape function (solid lines) for the molybdoarsenate complexes in the $(15,9,1)$ solution (C) derived with the use of the reference solution $G$ (upper drawing) and $\mathrm{H}$ (lower drawing). For comparison the shape function for an $\mathrm{Mo}_{9} \mathrm{AsO}_{34}$ group calculated from the crystal structure parameters and assuming a radius of $6.4 \AA$, is also plotted (dotted line). The dashed line gives the corresponding shape function after modifying the Mo positions as described in a previous paper. ${ }^{5}$ plex can be derived. The approximations, inherent in this method of derivation, can to some extent be estimated by using more than one reference solution.

Two different reference solutions were used: one, $\mathrm{G}$, previously shown to contain all molybdenum as $\mathrm{Mo}_{5} \mathrm{P}_{2} \mathrm{O}_{23}^{6-}$ complexes and the other, $\mathrm{H}$, containing all molybdenum as $\mathrm{Mo}_{7} \mathrm{O}_{24}^{6-}$ complexes. The shape functions derived from the scattering data for the solutions $\mathrm{C}$ and $\mathrm{F}$ with the use of each of the two reference solutions, $\mathrm{G}$ and $\mathrm{H}$, are shown in Figs. 5 ( $\mathrm{CG}$ and $\mathrm{CH}$ ) and 6 (FG and $\mathrm{FH})$. The parameters used in the derivations are given in Table 2.

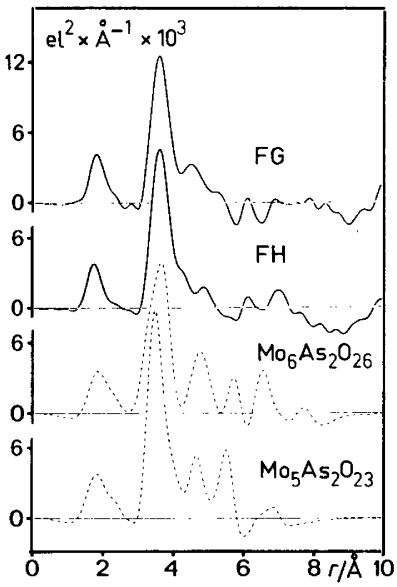

Fig. 6. The shape function (solid lines) for the molybdoarsenate complexes in the $(12,6,2)$ solution (F) derived with the use of the reference solutions $G$ (FG) and $\mathrm{H}(\mathrm{FH})$. For comparison the calculated shape functions for two assumed groups $\mathrm{Mo}_{6} \mathrm{As}_{2} \mathrm{O}_{26}$ and $\mathrm{Mo}_{5} \mathrm{As}_{2} \mathrm{O}_{23}$ (dashed lines), illustrated in Fig. 7, have been plotted.

Table 2. Parameters used in the calculations of shape functions. A formula given within brackets indicates that the corresponding complex has not been found in discrete form in a crystal structure.

\begin{tabular}{|c|c|c|c|c|c|c|}
\hline \multirow[t]{2}{*}{ Complex } & \multirow[t]{2}{*}{$\begin{array}{l}\text { Intramolecular } \\
\text { distances }\end{array}$} & \multicolumn{3}{|c|}{ Temperature coefficients $\left[\AA^{2}\right]$} & \multicolumn{2}{|c|}{$\begin{array}{l}\text { Intermolecular } \\
\text { interactions }\end{array}$} \\
\hline & & Mo-Mo & $\mathrm{Mo}-\mathrm{O}$ & $\mathrm{O}-\mathrm{O}$ & $R[\AA]$ & $B\left[\AA^{2}\right]$ \\
\hline \multirow{7}{*}{ 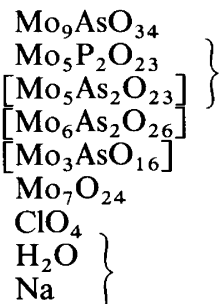 } & Ref. 6 & 0.006 & 0.006 & 0.006 & 6.4 & 0.02 \\
\hline & Ref. 15 & 0.004 & 0.002 & 0.000 & 5.0 & 0.02 \\
\hline & Ref. 1,11 & 0.010 & 0.010 & 0.010 & 5.5 & 0.02 \\
\hline & Ref. 6 & 0.006 & 0.006 & 0.006 & 4.5 & 0.02 \\
\hline & Ref. 16 & 0.002 & 0.004 & 0.006 & 5.5 & 0.02 \\
\hline & $\mathrm{Cl}-\mathrm{O} 1.43 \AA$ & & 0.002 & 0.002 & 2.8 & 0.02 \\
\hline & & & & & 1.8 & 0.02 \\
\hline
\end{tabular}

Acta Chem. Scand. A 32 (1978) No. 8 


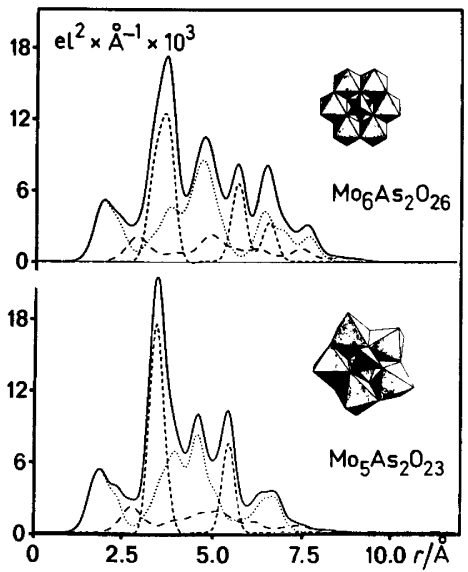

Fig. 7. Calculated shape functions for an $\mathrm{Mo}_{6} \mathrm{As}_{2} \mathrm{O}_{26}$ group with the structure suggested by Pettersson (upper drawing) and an $\mathrm{Mo}_{5} \mathrm{As}_{2} \mathrm{O}_{23}$ group assumed to have the same structure as $\mathrm{Mo}_{5} \mathrm{P}_{2} \mathrm{O}_{23}^{6-}$. The separate contributions from $\mathrm{Mo}(\mathrm{As})-\mathrm{Mo}$ (As) (short dashes), $\mathrm{Mo}(\mathrm{As})-\mathrm{O}$ (dots), and $\mathrm{O}-\mathrm{O}$ (long dashes) interactions are also given.

In agreement with the conclusions already made, the $(15,9,1)$ solution gives a shape function closely similar to that calculated from the crystal structure parameters ${ }^{6}$ for the $\mathrm{Mo}_{9} \mathrm{AsO}_{34}$ unit. Similar deviations, although apparently somewhat less pronounced, seem to occur as were found for the corresponding phosphate and which were then related to a slight difference between the Mo positions when the complexes occurred in crystals and in solutions. ${ }^{5}$

The $(12,6,2)$ solution leads to a shape function which is characteristically different from that of the $(15,9,1)$ complex. It indicates the absence of long intramolecular distances, which seems to suggest that the $(12,6,2)$ complex is a small complex. A structure for the $(p, 6,2)$ complexes, based on the structure of $\mathrm{TeMo}_{6} \mathrm{O}_{24}^{6-}$ determined by Evans, ${ }^{11}$ has been suggested by Pettersson, ${ }^{1}$ and is shown in Fig. 7. A $(10,6,2)$ complex with this structure would have the formula $\mathrm{Mo}_{6} \mathrm{As}_{2} \mathrm{O}_{26}^{6-}$ and a $(12,6,2)$ complex would correspond to its disprotonated from. Filowitz and Klemperer ${ }^{12}$ have interpreted ${ }^{17} \mathrm{O}$ NMR spectra of the anions $(\mathrm{OAs})_{2} \mathrm{Mo}_{6} \mathrm{O}_{24}^{6-}$ and $\left(\mathrm{C}_{6} \mathrm{H}_{5} \mathrm{As}\right)_{2} \mathrm{Mo}_{6} \mathrm{O}_{24}^{4-}$ in solution to be consistent with such a structure. The same structure has been found for the anions $\mathrm{Mo}_{8} \mathrm{O}_{26}^{4-}$ in crystals of $\left[\mathrm{N}\left(\mathrm{C}_{4} \mathrm{H}_{9}\right)_{4}\right]_{4} \mathrm{Mo}_{8} \mathrm{O}_{26}{ }^{13}$ and $\left(\mathrm{CH}_{3} \mathrm{As}\right)_{2} \mathrm{Mo}_{6} \mathrm{O}_{24}^{4-}$ in crystals of $\left[\mathrm{N}\left(\mathrm{CH}_{3}\right)_{4}\right]_{2} \mathrm{Na}_{2}\left[\left(\mathrm{CH}_{3} \mathrm{As}\right)_{2} \mathrm{Mo}_{6} \mathrm{O}_{24}\right]$.-
$6 \mathrm{H}_{2} \mathrm{O}^{14}$ The calculated shape function for an $\mathrm{Mo}_{6} \mathrm{As}_{2} \mathrm{O}_{26}$ group having this structure is given in Fig. 7 and is compared in Fig. 6 with the shape function derived from the $(12,6,2)$ solution. In the same figures similar comparisons are made for an assumed $\mathrm{Mo}_{5} \mathrm{As}_{2} \mathrm{O}_{23}$ group having the same structure as $\mathrm{Mo}_{5} \mathrm{P}_{2} \mathrm{O}_{23}^{6-}$, which, in its diprotonated form. would be the dominant complex in the molybdophosphate system at the concentrations used for the $(12,6,2)$ molybdoarsenate solution. It seems unlikely that the structure of the complexes in the $(12,6,2)$ solution can be closely related to any of these complexes, because of the absence in the derived shape function of the long intramolecular interactions, clearly recognizable in the functions calculated for the $\mathrm{Mo}_{6} \mathrm{As}_{2} \mathrm{O}_{26}$ and the $\mathrm{Mo}_{5} \mathrm{As}_{2} \mathrm{O}_{23}$ structures. No clear indications of long intramolecular interactions are present in the distribution curve, with the possible exception of the small peak at about $6.1 \AA$ that can be observed in both the FG and the FH curves in Fig. 6. Its position corresponds approximately to that of the second largest peak in the shape function for the $\mathrm{Mo}_{9} \mathrm{AsO}_{34}$ group (Figs. 4 and 5) and it may, therefore, indicate the presence of a minor amount of this complex in the solution.

Thus, if we accept the conclusions from the potentiometric and the spectrophotometric measurements, that the $(12,6,2)$ solution contains a single dominant molybdoarsenate complex, the scattering data strongly suggest that this complex cannot contain as many as 6 Mo atoms. Because of experimental difficulties the potentiometric measurements could not be carried out over as wide a concentration range as would have been desirable. ${ }^{1}$ Therefore, although the ratio between the number of Mo and As atoms in the complex is probably well established, the number of Mo atoms in the complex is less certain. A recalculation of the potentiometric data, using a slightly extended set of data, shows that the inclusion of a $(6,3,1)$ complex in addition to the original $(12,6,2)$ complex improves the agreement between observed and calculated data. The $(12,6,2)$ complex, however, remains the dominant complex.

A $(6,3,1)$ complex would be more consistent with the scattering data since the $\mathrm{MoO}_{6}$ octahedra can be directly connected without the occurrence of long Mo-Mo distances. Two conceivable structures for a complex of this type are shown in Fig. 9. They have both been cut out from the $\mathrm{Mo}_{9} \mathrm{AsO}_{34}$ structure and can be written as $\mathrm{Mo}_{3} \mathrm{AsO}_{16}^{9-}-$ or as $\mathrm{H}_{7} \mathrm{Mo}_{3} \mathrm{AsO}_{16}^{2-}$ in order to correspond to a 


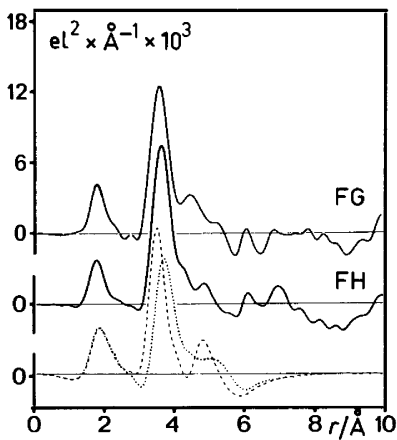

Fig. 8. The shape functions FG and FH (solid lines) compared with calculated shape functions for an $\mathrm{Mo}_{3} \mathrm{AsO}_{16}$ group containing edge-sharing $\mathrm{MoO}_{6}$ octahedra (dashed line) or corner sharing $\mathrm{MoO}_{6}$ octahedra (dotted line). The assumed structures are illustrated in Fig. 9. Values of $4.5 \AA$ were used for the radii.

$(6,3,1)$ complex. In one of them the three $\mathrm{MoO}_{6}$ octahedra are joined by common edges and in the other by common corners. The corresponding shape functions calculated with the use of the crystal structure parameters for the $\mathrm{Mo}_{9} \mathrm{AsO}_{34}$ group, are compared in Fig. 8 with the shape function derived from the $(12,6,2)$ solution.

\section{CONCLUSIONS}

The results of the X-ray scattering measurements on molybdoarsenate solutions are in the main consistent with results previously obtained from potentiometric and spectrophotometric measurements. ${ }^{1.2}$ For solutions with $\mathrm{Mo} /$ As ratios $\sim 9$ the occurrence of complexes with the composition $\left(\mathrm{H}^{+}\right)_{p}\left(\mathrm{MoO}_{4}^{2-}\right)_{9}\left(\mathrm{HAsO}_{4}^{2-}\right)$ has been suggested on the basis of emf data. ${ }^{1,2}$ This is consistent with the results of the scattering measurements which show the structure of the complexes in such solutions to be independent of the hydrogen ion concentration and to be basically the same as that of the $\mathrm{Mo}_{9} \mathrm{AsO}_{31}\left(\mathrm{OH}_{2}\right)_{3}^{3-}$ complexes found in crystals of $\mathrm{Na}_{3} \mathrm{Mo}_{9} \mathrm{AsO}_{31}\left(\mathrm{OH}_{2}\right)_{3} .12-13 \mathrm{H}_{2} \mathrm{O}$. ${ }^{6}$ Similar results have been previously obtained for the molybdophosphate system. ${ }^{2,3,5}$ Thus the existence of a series of protonated heteropolymolybdates with the general formula $\mathrm{H}_{y} \mathrm{Mo}_{9} \mathrm{O}_{31}(\mathrm{OH})_{3}{ }^{(6-y)-}$, where $\mathrm{X}$ stands for pentavalent phosphorus or arsenic, with $y=0-3$, seems to be firmly established.
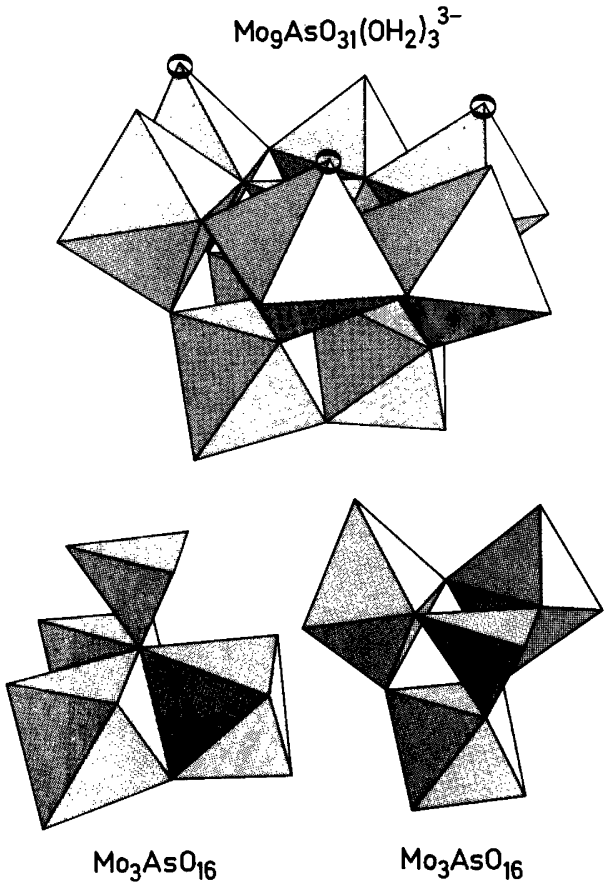

Fig. 9. The structure of an $\mathrm{Mo}_{9} \mathrm{AsO}_{34}$ group as found in crystals of $\mathrm{Na}_{3} \mathrm{Mo}_{6} \mathrm{AsO}_{31}\left(\mathrm{OH}_{2}\right)_{3} .12-13$ $\mathrm{H}_{2} \mathrm{O}^{6}$ The Mo-coordinated water molecules are marked by circles. Two groups which have both been cut out from this structure and which both have the composition $\mathrm{Mo}_{3} \mathrm{AsO}_{16}$ are illustrated in the lower half of the figure.

For solutions with Mo/As ratios $\sim 3$ the best interpretation of the emf data has indicated the predominant complexes to have the composition $\left(\mathrm{H}^{+}\right)_{p}\left(\mathrm{MoO}_{4}^{2-}\right)_{6}\left(\mathrm{HAsO}_{4}^{2-}\right)_{2}$ with $p=10-12$. This type of complexes was not found in the phosphate system, where complexes $\left(\mathrm{H}^{+}\right)_{p}\left(\mathrm{MoO}_{4}^{2-}\right)_{5}\left(\mathrm{HPO}_{4}^{2-}\right)_{2}$, with $p=8-10$ present only to a minor extent in the arsenate system, were found to be dominant and to have the same structure as that of the discrete units $\mathrm{Mo}_{5} \mathrm{P}_{2} \mathrm{O}_{23}^{6-}$ occurring in crystals. The scattering data confirm that the structure of the complexes in $(12,6,2)$ molybdoarsenate solutions differs from that found for the complexes in corresponding molybdophosphate solutions. The structure of the $(12,6,2)$ molybdoarsenate complexes cannot be uniquely derived from the limited information contained in the solution scattering data, but these data indicate that the complexes are small and may contain fewer Mo atoms than the six previously suggested. The

Acta Chem. Scand. A 32 (1978) No. 8 
$(12,6,2)$ complex can be obtained in high concentration in solution in contrast to the first two members of the series (Fig. 1), which might indicate a difference in structure. Since the $(10,6,2)$ and the $(11,6,2)$ complexes cannot be obtained in sufficiently high concentrations a comparison by means of LAXS measurements cannot be made. To clarify this point, further potentiometric measurements, covering a larger concentration range, and structure determinations of crystals prepared from these solutions will be needed. Work in this direction is in progress.

Acknowledgements. The work has been supported by the Swedish Natural Science Research Council. We thank Ing. Ernst Hansen for skilful technical assistance.

\section{REFERENCES}

1. Pettersson, L. Acta Chem. Scand. A 29 (1975) 677.

2. Pettersson, L. Equilibrium and Structure Studies of Aqueous Three Component Polyanion Complexes Formed in the Systems $\mathrm{H}^{+}-\mathrm{MoO}_{4}^{2-}-$ $\mathrm{HPO}_{4}^{2-}, \mathrm{H}^{+}-\mathrm{MoO}_{4}^{2-}-\mathrm{HAsO}_{4}^{2-}$ and $\mathrm{H}^{+}-$ $\mathrm{MoO}_{4}^{2-}$-(D-)mannitol, Diss., Umeå Universitet, Umeå 1974.

3. Pettersson, L. Chem. Scr. 7 (1975) 145.

4. Johansson, G., Pettersson, L. and Ingri, N. Acta Chem. Scand. A 28 (1974) 1119.

5. Johansson, G., Pettersson, L. and Ingri, N. Acta Chem. Scand. A 32 (1978) 407.

6. Johansson, G. Acta Chem. Scand. To be published.

7. Johansson, G. Acta Chem. Scand. 25 (1971) $2787 ; 20$ (1966) 553.

8. Pocev, S. and Johansson, G. Acta Chem. Scand. 27 (1973) 2146.

9. Johansson, G. and Sandström, M. Chem. Scr. 4 (1973) 195.

10. Strandberg, R. Acta Chem. Scand. A 28 (1974) 217.

11. Evans, H. T., Jr. Acta Crystallogr. B 30 (1974) 2095.

12. Filowitz, M. and Klemperer, W. G. Chem. Commun. (1976) 233.

13. Fuchs, J. and Hartl, H. Angew. Chem. 88 (1976) 385.

14. Kwak, W., Rajkovic, L. M., Stalick, J. K., Pope, M. T. and Quicksall, C. O. Inorg. Chem. 15 (1976) 2778.

15. Strandberg, R. Acta Chem. Scand. 27 (1973) 1004.

16. Sjöbom, K. and Hedman, B. Acta Chem. Scand. 27 (1973) 3673.

Received April 17, 1978. 